\title{
Studies in Zebrafish Demonstrate That CNNM2 and NT5C2 Are Most Likely the Causal Genes at the Blood Pressure-Associated Locus on Human Chromosome 10q24.32
}

\author{
Krishan K. Vishnolia 1,2,3, Celine Hoene ${ }^{1,2,3}$, Karim Tarhbalouti ${ }^{1,2,3}$, Julian Revenstorff ${ }^{1,2,3}$, \\ Zouhair Aherrahrou ${ }^{1,2,3}$ and Jeanette Erdmann ${ }^{1,2,3 *}$ \\ ${ }^{1}$ Institute for Cardiogenetics, University of Luebeck, Luebeck, Germany, ${ }^{2}$ DZHK (German Research Centre for Cardiovascular \\ Research), Partner Site Hamburg/Luebeck/Kiel, Luebeck, Germany, ${ }^{3}$ University Heart Centre Luebeck, Luebeck, Germany
}

OPEN ACCESS

Edited by:

Guido laccarino,

University of Naples Federico II, Italy

Reviewed by:

Gu Dongfeng,

Southern University of Science and

Technology, China

Speranza Rubattu,

Istituto Neurologico Mediterraneo

Neuromed (IRCCS), Italy

Nicole Marie Davis Armstrong, University of Alabama at Birmingham,

United States

*Correspondence:

Jeanette Erdmann

Jeanette.erdmann@uni-luebeck.de

Specialty section:

This article was submitted to Hypertension,

a section of the journal

Frontiers in Cardiovascular Medicine

Received: 07 April 2020

Accepted: 30 June 2020

Published: 02 September 2020

Citation:

Vishnolia KK, Hoene C, Tarhbalouti K,

Revenstorff J, Aherrahrou Z and Erdmann J (2020) Studies in Zebrafish

Demonstrate That CNNM2 and

NT5C2 Are Most Likely the Causal

Genes at the Blood

Pressure-Associated Locus on

Human Chromosome 10q24.32.

Front. Cardiovasc. Med. 7:135.

doi: 10.3389/fcvm.2020.00135
Background: Globally, high blood pressure (BP) is the most important risk factor for cardiovascular disease. Several genome-wide association studies (GWAS) have identified variants associated with BP traits at more than 535 chromosomal loci with genome-wide significance. The post-GWAS challenge is to annotate the most likely causal gene(s) at each locus. Chromosome 10q24.32 is a locus associated with BP that encompasses five genes: CYP17A1, BORCS7, AS3MT, CNNM2, and NT5C2 and warrants investigation to determine the specific gene or genes responsible for the phenotype.

Aim: To identify the most likely causal gene(s) associated with BP at the 10q24.32 locus using zebrafish as an animal model.

Results: We report significantly higher blood flow, increased arterial pulse, and elevated linear velocity in zebrafish larvae with cnnm2 and nt5c2 knocked down using gene-specific splice modification transcriptional morpholinos, compared with controls. No differences in blood-flow parameters were observed after as $3 m t$, borcs7, or cyp17a1 knockdown. There was no effect on vessel diameter in animals with any of the four genes knocked down. At the molecular level, expression of hypertension markers (crp and ace) was significantly increased in cnnm2 and $n t 5 c 2$ knockdown larvae. Further, the results obtained by morpholino knockdown were validated using zebrafish knockout (KO) lines with cnnm2 and nt5c2 deficiency, again resulting in higher blood flow, increased arterial pulse, and elevated linear velocity. Analysis of $n t 5 c 2 a \mathrm{KO}$ larvae demonstrated that lack of this gene resulted in reduced expression of cnnm2a, with reciprocal downregulation of $n t 5 c 2 a$ in cnnm2a KO larvae. Staining of whole-blood smears from $n t 5 c 2$ mutants revealed that $\mathrm{KO}$ of this gene might be associated with an acute lymphoblastic leukemia phenotype, consistent with literature reports. Additional experiments were designed based on previous literature on cnnm2a mutant zebrafish revealed impaired renal function, high levels of renin, and significantly increased expression of the ren gene, leading us to hypothesize that the observed elevated blood-flow parameters may be attributable to triggering of the renin-angiotensin-aldosterone signaling pathway. 
Conclusion: Our zebrafish data establish CNNM2 and NT5C2 as the most likely causal genes at the 10q24.32 BP locus and indicate that they trigger separate downstream mechanistic pathways.

\section{Keywords: blood-pressure, zebrafish, GWAS \& Post-GWAS, 10q24.32 locus, nt5c2 \& cnnm2}

\section{INTRODUCTION}

Blood pressure (BP) is reportedly the strongest heritable risk factor for stroke and coronary artery disease (CAD), leading to its prominent role in global morbidity and mortality (1). Pressure exerted by circulating blood on the blood vessels (mainly the large arteries of the systematic circulation) is termed BP. As per American College of Cardiology (ACC)/American Heart Association (AHA) Hypertension guidelines (2017), BP was classified in four stages, i.e., normal BP at $<120 / 80 \mathrm{~mm}$ $\mathrm{Hg}$, elevated at $120-129 /<80 \mathrm{~mm} \mathrm{Hg}$, stage 1 hypertension $130-139 / 80-89 \mathrm{mmHg}$, and stage 2 hypertension at $\geq 140 / 90$ $\mathrm{mmHg}$ (2). High BP itself was responsible for 7.8 million deaths and loss of 148 million disability life years worldwide in 2015 alone (1). Factors contributing to BP level in an individual can be only determined after taking into consideration complex interactions between his/her life course exposures and genetic predispositions, as shown by several familial studies (3-5).

The development of genome-wide association studies (GWAS) has ensured identification of numerous genetic variants and their associations with diseases. Nevertheless, these variants provide limited knowledge above heritability projected in previous family based studies; that is, there is missing heritability, which remains unidentified (3). Expansion of GWAS in recent years has broadened our understanding by identifying associations of numerous novel genetic variants with specific diseases. Evangelos et al. recently conducted the largest GWAS for BP traits in over one million people of European ancestry and reported the identification of 535 novel loci, representing new biological insights into BP (6).

There is a plethora of literature available describing the overlap and association between cardiovascular diseases and BP (6-8). In a recent publication, Evangelos et al. reported associations of angiogenesis and vascular smooth muscle cell regulating genes, such as vascular endothelial growth factor A (VEGFA), fibroblast growth factor (FGF5), and FGF9, with $\mathrm{BP}$ (6). Lipid-related genes, such as apolipoprotein $\mathrm{E}(A P O E)$, low-density lipoprotein receptor-related protein 4 (LRP4), and apolipoprotein L domain containing 1 gene (APOLD1), were also observed to have strong associations with multiple cardiometabolic traits (6).

The zebrafish, Danio rerio, is a small tropical freshwater fish that lives in the rivers of northern India, northern Pakistan, Nepal, and Bhutan. The small size and ease of culture of this organism (9) mean that it is well-suited to developmental and genetic analyses, and it has become established as a powerful model organism for the study of vertebrate biology over the past 20 years. Additional advantages of zebrafish include their ability to produce large numbers of offspring (200-300, compared with an average for mice of 5-10 offspring), the fact that they are genetically similar to humans (90\% at the genomic level) (10), and the ease with which their genes can be manipulated in the laboratory (11). Further, a crucial factor in the establishment of zebrafish as an animal model is that their larvae remain optically transparent during the first month of development, enabling temporal observation of developmental biology, fluorescent proteins, and probes in living animals (12).

Exploitation of the optical transparency of zebrafish larvae has led to the development of the platform MicroZebraLab software (ViewPoint), which allows non-invasive simultaneous measurement of differential cardiac chamber beat frequencies, blood-flow rates, vasodilation/constriction, stroke volume, and linear velocity (13). The rapid development of the two-chambered zebrafish heart includes the beginning of contractions, as early as $26 \mathrm{~h}$ post-fertilization (hpf), initiation of looping by $48 \mathrm{hpf}$, and full vascular tree development by $72 \mathrm{hpf}$ (14). The adult zebrafish action potential presents similarities with that of humans; for example, the zebrafish action potential upstroke is led by $\mathrm{Na}^{+}$channels and L-type $\mathrm{Ca}^{2+}$ channels, which are important for the plateau phase. Although zebrafish do not possess functional slowly activating $\mathrm{K}^{+}$currents, the presence of cardiac T-type $\mathrm{Ca}^{2+}$ currents suggests that the electro-physiology of the adult zebrafish may be comparable to the human fetal phenotype (15). Vascular development begins with the migration of angioblasts at $24 \mathrm{hpf}$, which initiate the formation of two major axial vessels, the dorsal aorta, and the posterior cardinal vein, which are fully formed and begin to carry blood at $30 \mathrm{hpf}$ (13). Even at 20 days post-fertilization, very few vascular smooth muscle cells can be detected in the caudal vein, probably because venous control of $\mathrm{BP}$ is less critical in fish than in terrestrial animals, where gravitational influences are greater (13).

Zebrafish serves as a simple vertebrate model, enabling profiling of novel cardiovascular drugs before initiating mammalian toxicity tests. Recent study investigated the translational power of zebrafish (in a meta-analysis) in comparison to rat, dog, and human to three model compounds (propranolol, losartan, and captopril), which act as modulators on two key systems (beta-adrenergic and renin-angiotensin systems) regulating cardiovascular functions (16). Results showed that the zebrafish cardiovascular responses were highly similar (over 80\%) to those in humans against the model compounds, both in direction and in effect size. Considering these results and all the advantages mentioned earlier, zebrafish sets out to be an ideal model system for early-stage cardiovascular and/or blood-flow investigations (16).

As mentioned above, hundreds of genes and loci associated with BP phenotypes have been identified by GWAS; however, 
limited functional studies to support the GWAS findings have been reported to date. Most loci associated with a BP phenotype encompasses a number of genes, while understanding of which gene (or genes) may be causal for the phenotype, and whether they are protective or detrimental, is lacking. Here, we conducted a proof-of-principal study, which could serve as a blueprint for the investigation of several other loci associated with BP, using zebrafish as a model organism. In the current study, we chose to dissect the chromosome 10q24.32 BP locus, which encompasses five genes, CYP17A1, BORCS7 (labeled as C10orf32), AS3MT, CNNM2, and NT5C2 ${ }^{17}$ (Figure 1), with the aims of (1) determining the causal gene(s) specific for the $\mathrm{BP}$ phenotype and (2) unraveling the pathomechanisms linking the gene(s) to the phenotype.

A
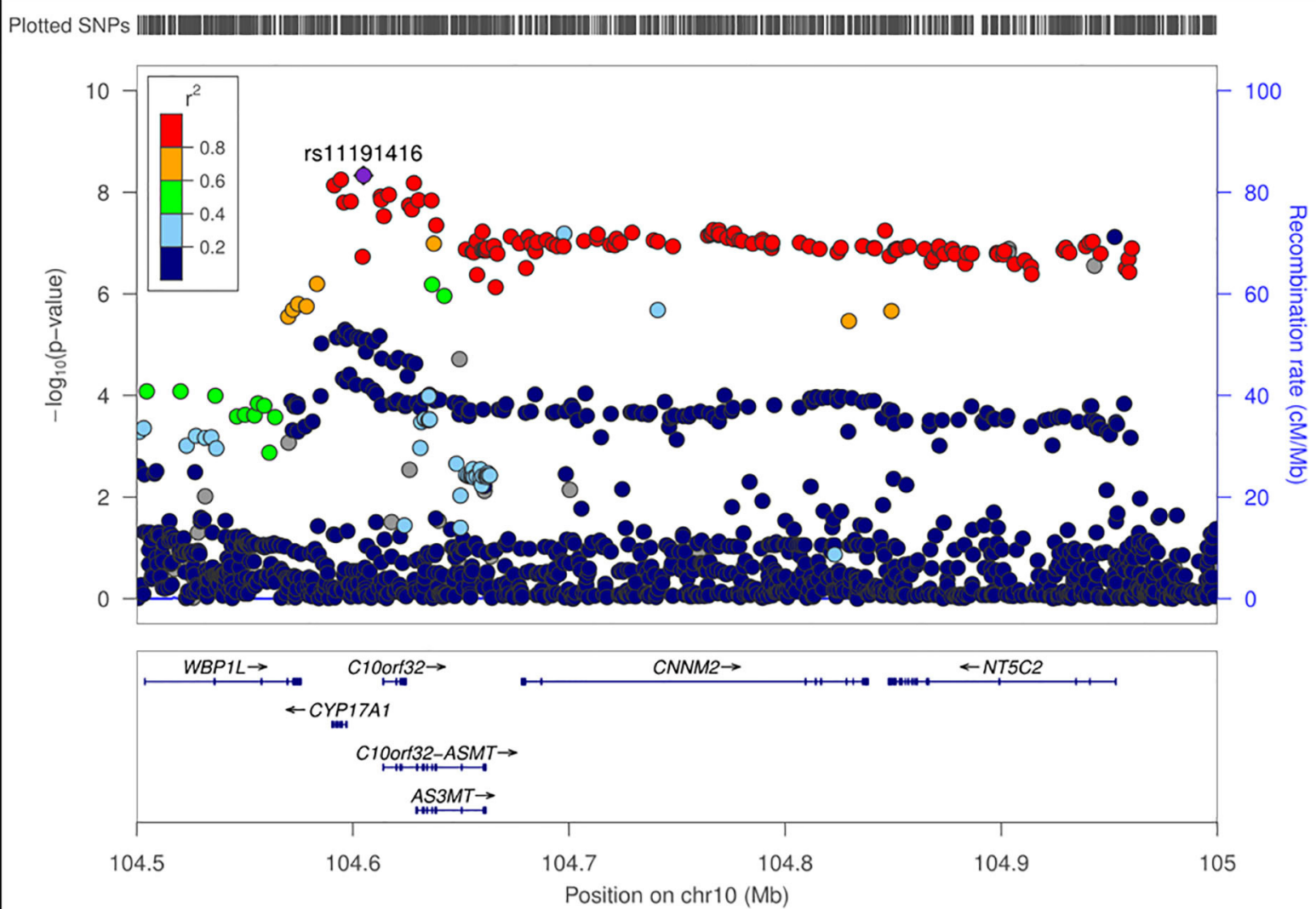

B

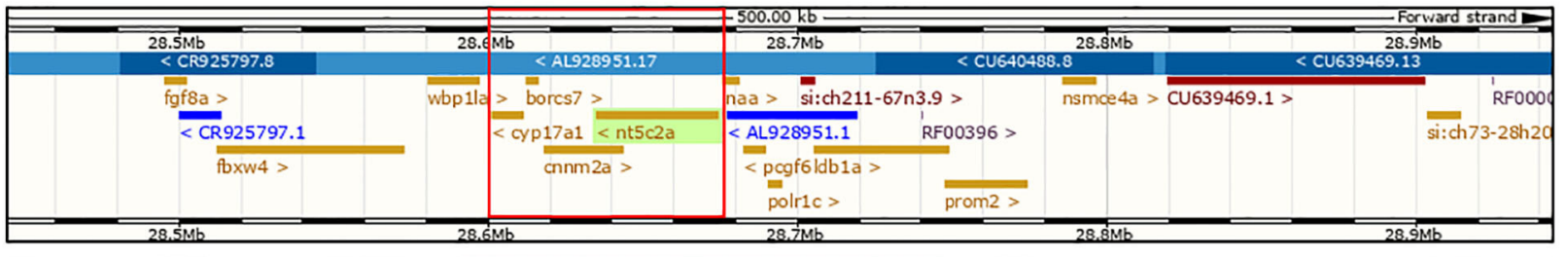

C

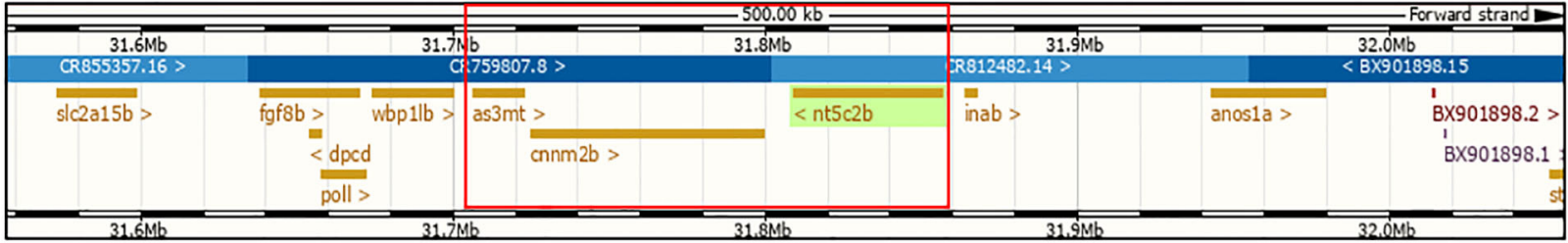

FIGURE 1 | (A) Regional association plot for human locus 10q24.32 on chromosome 10 showing genome wide significant single nucleotide polymorphisms for blood pressure phenotype. Figure adapted from (17). (B) First part of 10q24.32 locus conserved in zebrafish genome at chromosome 13 encompassing "a" paralogs of cnnm2, nt5c2, and cyp17a1 with borcs7. (C) Second part of 10q24.32 locus region conserved in zebrafish genome at chromosome 1 encompassing "b" paralogs of cnnm2 and $n t 5 c 2$, along with as $3 m t$ genes. 
Newton-Cheh et al. in 2009 identified 10q24.32 locus in human to be genome wide associated with blood pressure phenotype (17). Genes encompassed on locus 10q24.32 from human were found to be conserved in zebrafish on two different chromosomes along with NT5C2 and CNNM2 genes having two paralogs each. As highlighted in Figure 1, in zebrafish genome cnnm $2 a, c y p 17 a 1$, and $n t 5 c 2 a$ genes were encompassed on chromosome 13 (Figure 1B) and as $3 m t, c n n m 2 b$, and $n t 5 c 2 b$ genes were encompassed on chromosome 1 (Figure 1C). As per ensemble database chromosome 13 in the zebrafish genome, the borcs7 gene was based in between cyp17al and cnnm $2 a$; therefore, we included it too in our investigations. A publicly available eQTL database along with one eQTL search engine developed and published by our lab, i.e., Qtlizer from Genehopper (18), was used to determine the beta values associated with the risk alleles for each gene. All the five genes included in current study revealed both positive and negative beta values suggesting no concrete indication toward the expression of individual gene.

\section{METHODS}

\section{Zebrafish Maintenance}

Animal studies were performed in accordance with the guidelines of the animal studies committee of Schleswig-Holstein, Germany. $\mathrm{AB}$ wild-type, cnnm $2 a^{\text {sa14149 }}, c y p 17 a 1^{\text {sa22316}}$, and $n t 5 c 2 a^{\text {sa17723 }}$ strains were maintained under standard conditions at Fraunhofer Institute of Marine Biotechnology (EMB, Luebeck, Germany), as previously described in The Zebrafish book $(19,20)$. The zebrafish mutant lines, cnnm $2 a$ and cyp17a1, were purchased from the Zebrafish International Resource Center (ZIRC, University of Oregon, USA). AB wild-type and $n t 5 c 2 a$ mutant lines were purchased from the European Zebrafish Resource Center (EZRC, Germany).

\section{Genotyping}

The genotyping was performed according to previously described protocol (19), following which DNA was extracted using the DNeasy Blood and Tissue Kit (Qiagen, Germany), as per the manufacturer's protocol. Fragments containing mutations were amplified using specific genotyping primers. PCR conditions are provided in Supplementary File 1, and primer sequences are listed in Table 1. Following PCR, samples from cyp17a1 mutants were sent for Sanger sequencing at Seqlab/Microsynth, Germany, whereas amplicons from cnnm $2 a$ and $n t 5 c 2 a$ mutants were genotyped by restriction fragment length polymorphism (RFLP), which involved digestion with TaqI and BseMII (Thermo Fisher, Germany) enzymes, respectively, followed by electrophoresis of the digested products on $2 \%$ agarose gels alongside marker of molecular weight of $100 \mathrm{bp}$.

\section{Morpholino Injections}

Transcriptional splice modification morpholinos (5 ng/embryo) were injected into freshly hatched one-cell-stage $\mathrm{AB}$ wildtype zebrafish embryos. The following morpholinos were custom designed and purchased from Gene Tools (USA):
TABLE 1 | Table below consists of all the primer (forward and reverse) names and their respective sequences used during the whole study.

\begin{tabular}{|c|c|c|}
\hline $\begin{array}{l}\text { Gene } \\
\text { name }\end{array}$ & Sequence & Purpose \\
\hline cnnm2a_F & TTGTGCAGGACACTCTTTGC & RFLP \\
\hline cnnm2a_R & TGATGAAAACACAAGCCAACA & RFLP \\
\hline$n t 5 c 2 a \_F$ & TCTITACAGTTGCAAACCATGA & RFLP \\
\hline$n t 5 c 2 a \_R$ & CCTTGAGGATTGGAGAAAACA & RFLP \\
\hline cyp17a1_F & GGAATGGAAGAACCCTGAGC & Sequencing \\
\hline cyp17a1_R & ACTGAGCGCCGTCTGAAAT & Sequencing \\
\hline$n t 5 c 2 a \_F$ & CAACTTCTTGCGTGGTCCAG & $\begin{array}{l}\text { qPCR for MO-KD } \\
\text { efficiency }\end{array}$ \\
\hline$n t 5 c 2 a \_R$ & GGACCCAATCCACAGCATCT & $\begin{array}{l}\text { qPCR for MO-KD } \\
\text { efficiency }\end{array}$ \\
\hline cyp17a1_F & TCAGCGACAGGGGGAATCTA & $\begin{array}{l}\text { qPCR for MO-KD } \\
\text { efficiency }\end{array}$ \\
\hline cyp17a1_R & TTCAGAAAGCGTCCTGGGTC & $\begin{array}{l}\text { qPCR for MO-KD } \\
\text { efficiency }\end{array}$ \\
\hline cnnm2a_F & GTCAGCAGGGCAGAATCACT & $\begin{array}{l}\text { qPCR for MO-KD } \\
\text { efficiency }\end{array}$ \\
\hline cnnm2a_R & GGCGGGTCACCTTGATGTAG & $\begin{array}{l}\text { qPCR for } \mathrm{MO}-\mathrm{KD} \\
\text { efficiency }\end{array}$ \\
\hline borcs7_F & CTACTCAGTCAGGCAGCGAG & $\begin{array}{l}\text { qPCR for } \mathrm{MO}-\mathrm{KD} \\
\text { efficiency }\end{array}$ \\
\hline borcs7_R & GGTACTGCAAGTGGGTCGTT & $\begin{array}{l}\text { qPCR for MO-KD } \\
\text { efficiency }\end{array}$ \\
\hline as3mt_F & GGCACGTCACAGGTATCGAC & $\begin{array}{l}\text { qPCR for MO-KD } \\
\text { efficiency }\end{array}$ \\
\hline as3mt_R & ССТССGTССТTCAGAACACAA & $\begin{array}{l}\text { qPCR for MO-KD } \\
\text { efficiency }\end{array}$ \\
\hline$n t 5 c 2 b \_F$ & AGCAGTGTACAAATCGCCTGA & $\begin{array}{l}\text { qPCR for MO-KD } \\
\text { efficiency }\end{array}$ \\
\hline$n t 5 c 2 b \_R$ & CAGGCCCTCGCAGAAAGTTA & $\begin{array}{l}\text { qPCR for MO-KD } \\
\text { efficiency }\end{array}$ \\
\hline$c n n m 2 b \_F$ & TTCAGTCCCAGCCAGATGTC & $\begin{array}{l}\text { qPCR for MO-KD } \\
\text { efficiency }\end{array}$ \\
\hline$c n n m 2 b \_R$ & AGCCCTACTGACCACAAAGG & $\begin{array}{l}\text { qPCR for } \mathrm{MO}-\mathrm{KD} \\
\text { efficiency }\end{array}$ \\
\hline$n t 5 c 2 a \_F$ & GGTGCATCACAGAGTIITGTCA & $\mathrm{RT}$ \\
\hline$n t 5 c 2 a \_R$ & CACCAAGCCTCTTGTGGGAA & $\mathrm{RT}$ \\
\hline cyp17a1_F & GAGGCCACGGACTGTTACAA & $\mathrm{RT}$ \\
\hline cyp17a1_R & CACACATAGAGCTCGCCTCC & RT \\
\hline ren_F & GGGGCTITCTGAGTGAGGAC & $\mathrm{RT}$ \\
\hline ren_R & ATATCTGCCCCAACCGACAC & $\mathrm{RT}$ \\
\hline ace_F & GCTGGGCACTGACAAAATGG & $\mathrm{RT}$ \\
\hline ace_R & TCGGTGTAAGCGTTCCAGAC & RT \\
\hline crp_F & TGCTTCAGTTCAAGACGGCTA & RT \\
\hline crp_R & AACGCTGCATCCTTACTAGACTG & RT \\
\hline$E F 1 \alpha \_F$ & CTGGAGGCCAGCTCAAACAT & $\mathrm{RT}$ \\
\hline$E F 1 \alpha \_R$ & ATCAAGAAGAGTAGTACCGCTAGCATTAC & $\mathrm{RT}$ \\
\hline $\begin{array}{l}\beta- \\
\operatorname{actin} \_\end{array}$ & CGAGCTGTCTTCCCATCCA & RT \\
\hline $\begin{array}{l}\beta- \\
\operatorname{actin} R\end{array}$ & TCACCAACGTAGCTGTCTICTG & RT \\
\hline
\end{tabular}


as $3 m t$ ( $5^{\prime}$-AGTCCTGTCCCTTTGAACAAGAAAT-3'), borcs7 (5'-ATGTGTCGTATATTTACTTCTTGGC-3'), cnnm $2 a \quad\left(5^{\prime}-\mathrm{T}\right.$ CAGTGGATTAATTTCTGACCTGCA- $\left.3^{\prime}\right), \quad$ cnnm $2 b \quad\left(5^{\prime}\right.$-CA AGACGTTCATGGCACATACTATA-3'), cyp17a1 (5'-TGCAG TGACACTCACTTATCTTCTC- $\left.3^{\prime}\right), n t 5 c 2 a\left(5^{\prime}\right.$-AGATACTTGT TGATCTTACCTGCCA- $\left.3^{\prime}\right)$, and $n t 5 c 2 b \quad\left(5^{\prime}\right.$-GTCCATTT ATTTGTCTGATTTACCT- $3^{\prime}$ ). Quantification of genetic downregulation was performed by quantitative real-time PCR (real-time qPCR) using custom-designed primers (Table 1).

The efficiency of morpholino knockdown in larvae was assessed individually after measurement of blood-flow parameters, using real-time $\mathrm{qPCR}$ at the mRNA level. In this study, three biological samples were analyzed in triplicate for all real-time qPCR experiments. Total RNA was extracted using RNeasy kit (Qiagen, Germany), following the manufacturer's protocols. EF1 $\alpha$ and $\beta$-actin were used as internal housekeeping genes. Results were analyzed using the comparative threshold cycle method $\left(2^{-\Delta \Delta \mathrm{Ct}}\right)$, to compare expression levels in samples and controls, where control samples were set to a value of 1 .

\section{Blood-Flow Analysis}

The protocol for blood-flow measurement and analysis was adapted from (13). At $72 \mathrm{hpf}$, individual larvae were transferred into $80 \mu \mathrm{l}$ (total volume) of $0.1 \%$ low melting point agarose gel prepared in embryo system water, previously maintained at $17^{\circ} \mathrm{C}$ in a $1.5-\mathrm{ml}$ Eppendorf tube. Larvae in low melting point agarose gel were then transferred onto coverslips, followed by transfer onto an inverted microscope (Zeiss stereo, Discovery V20, Germany), mounted with high-speed video cameras (GRAS-03K2M-C, Point Gray, Richmond, Canada). Larvae were positioned, and a region of interest was selected, focused to capture the dorsal aorta, caudal to the swim bladder, and on top of the anal orifice, at 120 frames per second (fps) for $20 \mathrm{~min}$. The region of interest captured by the camera for video preparation is shown in Figure 2.

Once all the blood-flow videos were prepared for each group, in parallel with controls, they were analyzed using MicroZebraLab (Version 3.6, ViewPoint, Lyon, France), which detects changes in pixel density and combines them with vessel diameter to generate a flow rate $(\mathrm{nl} / \mathrm{sec})$ for every frame. Prior to analysis, the software was calibrated using a video recording of a hemocytometer grid, to establish the true width of the field of vision in microns. An area of each aortic blood vessel was carefully selected, avoiding any nearby capillaries, which might interfere with assessment of blood flow in the main vessel. Movement of erythrocytes within the tracked areas was detected by the software and used to compute the blood flow. In parallel, vessel diameter measurements were conducted by the software every $20 \mathrm{~s}$, following selection of a section of vessel and confirmation of two vessel edges. During analysis of video files to determine blood-flow parameters, the first 3 min of every video file was deleted, as this is the time needed for the zebrafish larvae to acclimatize to the conditions, as demonstrated in a previous publication (13) and also confirmed in our hands (data not included here). Blood-flow parameters were blindly measured from individual larvae for all the experiments without knowing their genotype, following which larvae was snap frozen for genotyping. After genotyping of individual larvae, data was statistically analyzed and plotted in graphs from heterozygote, homozygote, MO-knocked down larvae, and wild types.

\section{Ramipril Treatment}

Ramipril is an angiotensin-converting enzyme inhibitor used as a first-line medication for patients with high BP or congestive heart failure $(21,22)$. Zebrafish larvae (72 hpf) were first treated with ramipril in five groups ( $n=25$ larvae per group) at $0.1,0.2,0.3,0.4$, and $0.5 \mathrm{nM}$, to determine the most effective concentration, to be used in all subsequent experiments. To investigate its effects (i.e., whether blood-flow phenotype could be rescued), $\mathrm{AB}$ wild-type, cnnm $2 a$, and $n t 5 c 2 a$ mutant larvae were treated with ramipril for an hour before measurement of blood-flow parameters.

\section{Adult Zebrafish Blood Smear Staining}

Adult $n t 5 c 2 a$, cnnm $2 a$ mutants and $\mathrm{AB}$ wild-type zebrafish ( $n$ $=6$ per group) were anesthetized and sacrificed with the lethal dose of tricaine solution $(0.1 \mathrm{mg} / \mathrm{ml})$. Small blood samples (i.e., $\leq 0.4 \%$ of body weight) were collected from individual zebrafish, following the published protocol (23). Collected blood samples were smeared on normal glass slides (Thermo Fisher Scientific, Germany) and left to dry overnight. Following the manufacturer's protocol for May-Grünwald-Giemsa staining, slides were incubated in May-Grünwald stain (Merck, Germany) for $4 \mathrm{~min}$ followed by incubation in a 1:1 solution of MayGrünwald stain and May-Grünwald buffer. After washing with May-Grünwald buffer, slides were incubated in Giemsa stain for $20 \mathrm{~min}$, followed by washing with Giemsa buffer. Slides were air dried for a few hours before imaging under an inverted microscope (BZ9000, Keyence, Germany).

\section{Renin ELISA}

ELISAs were performed using the Mouse REN (Renin) ELISA kit (E-EL-M0061.96, Elabscience, Germany), according to the manufacturer's protocol. Most of the antibodies and kits used in zebrafish research are from mice or other species because of the species cross-reactivity; similarly, Mouse REN ELISA Kit was mentioned by the manufacturers to be working with zebrafish samples. Homozygote $n t 5 c 2 a \mathrm{KO}(n=10)$, cnnm $2 a$ $K O(n=10)$, and AB wild-type $(n=10)$ larvae (96 hpf) were homogenized in $300 \mu$ l of PBS in six groups per genotype ( $n$ $=60$ per genotype), to investigate renin levels. All analyses and calculations were conducted following the protocol provided by the ELISA kit manufacturer.

Renin levels were also investigated by extracting RNA from 96 hpf larvae ( $n=6$ larvae per group) and performing real-time qPCR for ren gene expression.

\section{Renal Function Assay}

We also investigated the kidney function of cnnm $2 a$ mutant zebrafish using a fluorescent clearance assay, where the optical transparency of the zebrafish was exploited to quantitatively monitor the clearance of fluorescent dye from the vasculature 

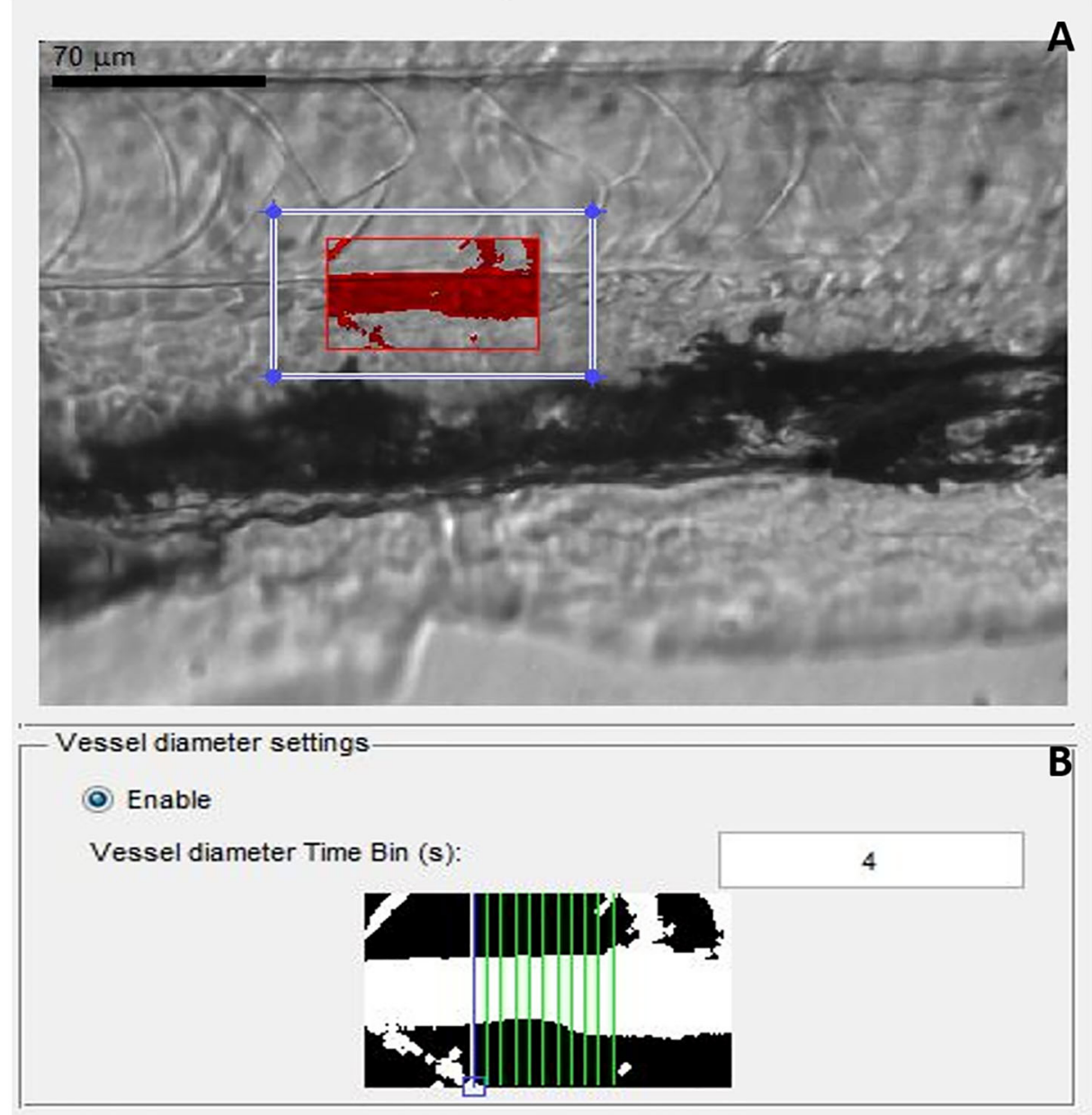

FIGURE 2 | Screen shot images of MicroZebraLab software while recording a video file for analyzing blood flow parameters from zebrafish. (A) Red box represents the area of dorsal aorta selected manually for preparing the video, (B) gray scale image from the software showing measurement of vessel diameter from where the blood flow parameters are measured.

and out through the kidney over time, to provide a measure of kidney function (24). Using a microcapillary, $1 \mathrm{nl}$ of Rhodamine B isothiocyanate-dextran (RITC-Dextran) (10,000 MW) dye $(5 \mathrm{mg} / \mathrm{ml})$ was microinjected into the pericardial cavity of $96 \mathrm{hpf}$ larvae ( $n=20$ per group). Fluorescence and bright-field images were captured in parallel from all groups (heterozygote, homozygote, and wild-type) after 3 , 12, and $24 \mathrm{~h}$ following the injections. All images were captured using the inverted Keyence microscope at 40 times magnification.

\section{Statistical Analysis}

All experiments were statistically analyzed using the program GraphPad Prism 6. After testing the normality, data (represented as mean $\pm \mathrm{SD}$ ) from experiments with only two groups were analyzed by non-parametric Student's $t$-test, while data from experiments with three or more groups were compared using two-way ANOVA, with multiple comparisons and without correction. The significance alpha $p$-value was adjusted by dividing it with the total number of tests performed.

\section{RESULTS}

All five genes encompassed in the human chromosome 10q24.32 and CAD and BP locus were found to be highly conserved between zebrafish and humans at both the cDNA and amino acid levels, respectively: as $3 m t, 60.98 \%$ and $73 \%$; borcs $7,75.53 \%$ and 65.84\%; cnnm $2 a, 76.66 \%$ and $84 \%$; cyp $17 a 1,47 \%$ and $65 \%$; and $n t 5 c 2 a, 77.47 \%$ and $95 \%$. Further, the " $b$ " paralogs of the $c n n m 2$ and $n t 5 c 2$ genes were more than $90 \%$ identical to the " $a$ " paralog according to the Ensembl database.

\section{Efficiency of Knockdown Using Morpholinos}

Quantification of genetic knockdown in larvae injected with splice modification transcription morpholinos was investigated 


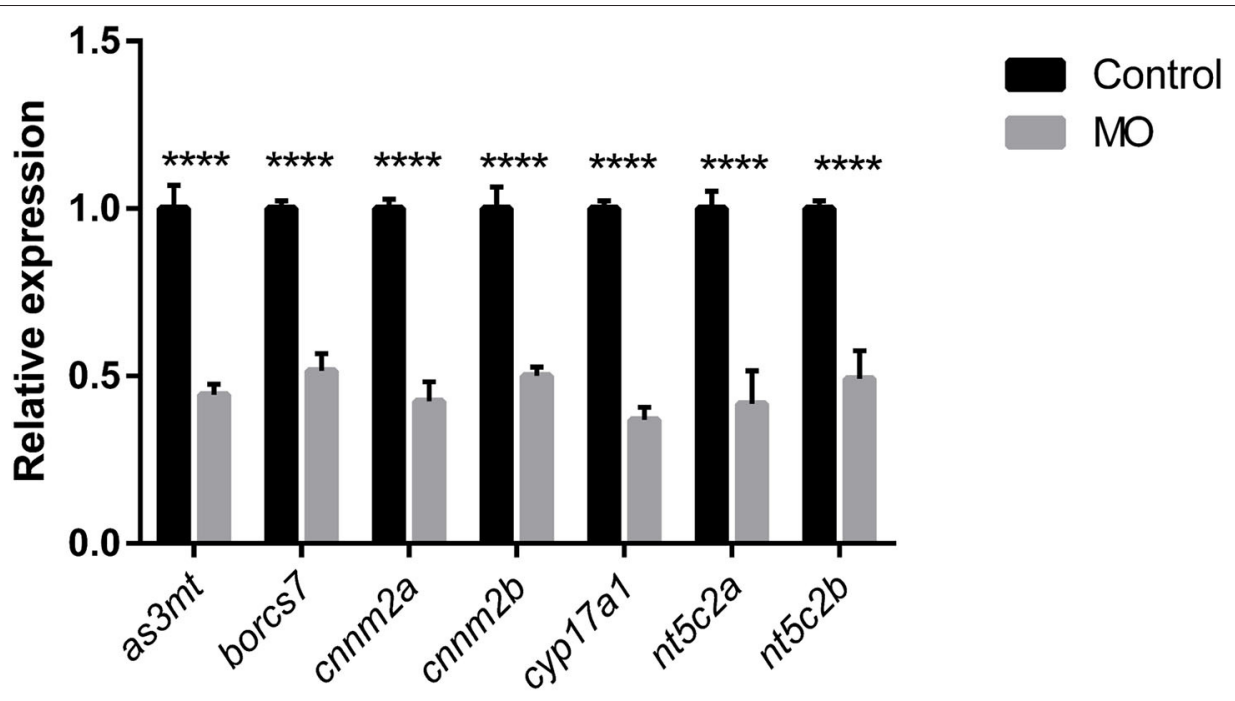

FIGURE 3 | Graph represents downregulation of the relative gene expression of as $3 m t$, borcs $7, c n n m 2 a, c n n m 2 b, c y p 17 a 1, n t 5 c 2 a, a n d ~ n t 5 c 2 b$ measured at $72 \mathrm{~h}$ post morpholino injections compare to their respective controls injected with control morpholinos from $n=10$ larvae per group. Error bars represents standard deviation and significance was set at $p<0.05 .{ }^{\star \star \star \star}$ represent the significant differences among the samples.

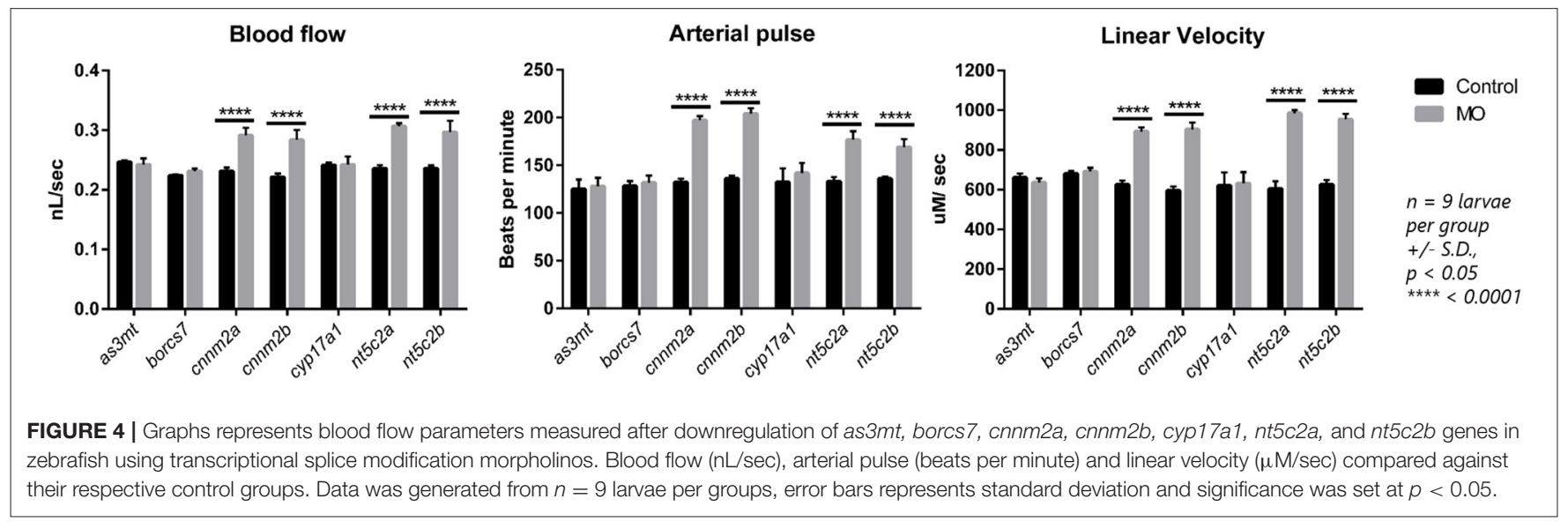

at $72 \mathrm{hpf}$ by measuring relative gene-expression levels compared with controls using real-time qPCR. We identified similar genetic downregulation, in the range of $\sim 40-50 \%$, using all our morpholinos (Figure 3).

\section{Determination of Blood-Flow Parameters in Larvae Following Morpholino}

\section{Knockdown}

We observed significant increases in blood-flow parameters (i.e., blood flow, arterial pulse, and linear velocity) after genetic knockdown of the cnnm 2 and $n t 5 c 2$ genes for both "a" and "b" paralogs using morpholinos. In contrast, no differences were detected on knockdown of the as $3 m t$, borcs 7 , and cyp17a1 genes. Further, no differences were observed in vessel diameter following knockdown of any of the genes (Figure 4).
RNA was extracted for gene-expression analysis from the same individual larvae used for measuring blood-flow parameters. Expression of molecular markers for hypertension and inflammation (25), including angiotensin-converting enzyme (ace) and C-reactive protein (crp), was significantly increased following knockdown of both cnnm2 and $n t 5 c 2$ (Table 2).

\section{Validation of Blood-Flow Analysis in Zebrafish Knockouts}

Zebrafish mutant lines available for the cnnm2a, cyp17a1, and $n t 5 c 2 a$ genes were purchased from international and European zebrafish resource centers. Validation experiments to evaluate blood-flow parameters in homozygote mutants of all three lines generated similar results, where $n t 5 c 2 a$ and $c n n m 2 a$ mutants exhibited significantly higher blood flow, arterial pulse, and linear 
TABLE 2 | Gene expression of hypertension and inflammation markers, i.e., ace and crp, post morpholino knockdown of cnnm2a, cnnm2b, nt5c2a, and $n t 5 c 2 b$ genes in zebrafish.

\begin{tabular}{|c|c|c|c|}
\hline \multirow{2}{*}{$\begin{array}{l}\text { Gene knocked } \\
\text { down } \\
\text { cnnm2a }\end{array}$} & \multirow{2}{*}{$\begin{array}{l}\text { Gene of interest } \\
\text { ace }\end{array}$} & \multicolumn{2}{|c|}{ Relative expression } \\
\hline & & $\begin{array}{l}\text { Control: } \\
\mathrm{MO}:\end{array}$ & $\begin{array}{l}1 \pm 0.169 \\
1.498 \pm 0.163^{\star}\end{array}$ \\
\hline & crp & $\begin{array}{l}\text { Control: } \\
\mathrm{MO}:\end{array}$ & $\begin{array}{l}1 \pm 0.124 \\
2.15 \pm 0.186^{\star}\end{array}$ \\
\hline \multirow[t]{2}{*}{ cnnm2b } & ace & $\begin{array}{l}\text { Control: } \\
\text { MO: }\end{array}$ & $\begin{array}{l}1 \pm 0.124 \\
1.375 \pm 0.143^{\star}\end{array}$ \\
\hline & crp & $\begin{array}{l}\text { Control: } \\
\mathrm{MO}:\end{array}$ & $\begin{array}{l}1 \pm 0.112 \\
1.98 \pm 0.118^{*}\end{array}$ \\
\hline \multirow[t]{2}{*}{$n t 5 c 2 a$} & ace & $\begin{array}{l}\text { Control: } \\
\mathrm{MO}:\end{array}$ & $\begin{array}{l}1 \pm 0.173 \\
2.55 \pm 0.4606^{\star}\end{array}$ \\
\hline & crp & $\begin{array}{l}\text { Control: } \\
\mathrm{MO}:\end{array}$ & $\begin{array}{l}1 \pm 0.102 \\
2.31 \pm 0.248^{*}\end{array}$ \\
\hline \multirow[t]{2}{*}{$n t 5 c 2 b$} & ace & $\begin{array}{l}\text { Control: } \\
\mathrm{MO}:\end{array}$ & $\begin{array}{l}1 \pm 0.132 \\
2.14 \pm 0.143^{*}\end{array}$ \\
\hline & crp & $\begin{array}{l}\text { Control: } \\
\mathrm{MO}:\end{array}$ & $\begin{array}{l}1 \pm 0.241 \\
1.97 \pm 0.118^{*}\end{array}$ \\
\hline
\end{tabular}

Data was generated and pooled from $n=6$ individual larvae per group. Star denotes the significant differences among the samples compare to their respective controls along with \pm standard deviation

velocity. No significant differences were observed in the bloodflow parameters of cyp17a1 mutants, and there was no significant alteration in vessel diameter in mutants of any of the three genes (Figure 5).

\section{Phenotype Rescue by Treatment With Ramipril}

Ramipril is a well-known vasodilator used as a first-line medication for hypertensive patients (21). $0.3 \mathrm{nM}$ concentration of ramipril was determined to be the most effective concentration for zebrafish larvae (Ab wild type), as the larvae treated with 0.4 and $0.5 \mathrm{nM}$ ramipril did not survive (Supplementary File 2) and a non-significant effect on blood flow was observed from 0.1 and $0.2 \mathrm{nM}$-treated zebrafish larvae (Ab wild type). Therefore, $0.3 \mathrm{nM}$ concentration of ramipril was used for all the subsequent phenotype rescue experiments (Figure 6). Zebrafish cnnm $2 a$ and $n t 5 c 2 a$ mutants and control $\mathrm{AB}$ wild-type fish were treated with ramipril $(0.3 \mathrm{nM})$ to investigate whether the blood-flow phenotypes of the mutants could be rescued by this drug. Blood-flow parameters measured from individual larvae $(n=6$ per group) demonstrated significant changes in mutant larvae compared with controls. Treatment with ramipril attenuated the blood-flow parameters in both mutant lines, which did not differ significantly from those of control larvae following treatment. Vessel diameter was significantly increased in both cnnm $2 a$ and $n t 5 c 2 a$ mutant larvae after treatment with Ramipril (Figure 6).

\section{Co-regulation of the nt5c2a and cnnm2a Genes in Zebrafish}

Data mining using the $4 \mathrm{C}$ database browser indicated that there may be an interaction between the regulation of the CNNM2 and NT5C2 genes in humans (26). To investigate this possibility, we evaluated the expression of the cnnm $2 a, c y p 17 a 1$, and $n t 5 c 2 a$ genes individually in zebrafish mutant larvae. We observed no expression of $n t 5 c 2 a$ in the cnnm $2 a$ mutants and a significantly lower expression of cnnm $2 a$ in $n t 5 c 2 a$ mutants (Figure 7). Both genes were expressed at normal levels in cyp17a1 mutants, and the housekeeping gene $\beta$-actin was expressed at normal levels in all the mutants.

\section{Staining of Whole Blood Samples From nt5c2a Mutants}

Blood was collected from adult $n t 5 c 2 a$ homozygote mutant zebrafish and wild-type animals as controls ( $n=6$ per group). Blood samples were smeared on slides for May-GrünwaldGiemsa staining. As shown in representative images (Figure 8), numbers of immature or multinucleated blood cells (highlighted using brown and black arrows in Figure 8) were significantly higher in blood smears from $n t 5 c 2 a$ mutant zebrafish relative to controls. This increased number of immature blood cells, lacking or disrupted cytoplasm around their nuclei, suggests an acute lymphoblastic leukemia (ALL) kind of phenotype, which has previously been reported with $n t 5 c 2 a$ gene mutation $(27,28)$.

\section{Measurement of Renin Levels in cnnm2a Knockouts by ELISA}

Renin levels were quantified in cnnm $2 a$ zebrafish larvae mutants and wild-type controls using a mouse ELISA, as species crossreactivity meant that it could also be used for analysis of zebrafish (see Methods section). As shown in Figure 8, renin levels in cnnm $2 a$ mutant larvae were significantly higher than those in $n t 5 c 2 a$ mutants and controls. Renin is a key player in the renin-angiotensin-aldosterone (RAAS) signaling pathway, which is associated with high $\mathrm{BP}(29,30)$; therefore, the high levels of renin in cnnm $2 a$ mutant zebrafish larvae indicate a potential mechanism underlying the observed high blood flow in this model.

Increased renin levels in the cnnm $2 a$ mutants were also supported by a significant difference in the expression levels of the ren gene in the mutants relative to controls (Figure 9).

\section{Assessment of Kidney Function in cnnm2a Knockouts}

Fluorescent images collected after injection of RITC-Dextran dye into cnnm $2 a$ mutants and control larvae were compared at various time points: 3,12 , and $24 \mathrm{~h}$ postinjection. Images acquired at $3 \mathrm{~h}$ postinjection confirmed that the injections had penetrated the pericardial cavities of the zebrafish larvae. Under normal conditions, more than half of the initial fluorescence was reduced from the blood over a $24 \mathrm{~h}$ period by secretion via the kidney (24). The images in Figure 10 clearly show that cnnm $2 a$ mutants were unable to filter the injected dye through the kidney and clear it by $24 \mathrm{~h}$ postinjection, unlike control larvae. Inability to clear the dye in the normal manner suggests possible kidney dysfunction in the cnnm $2 a$ zebrafish mutants. 

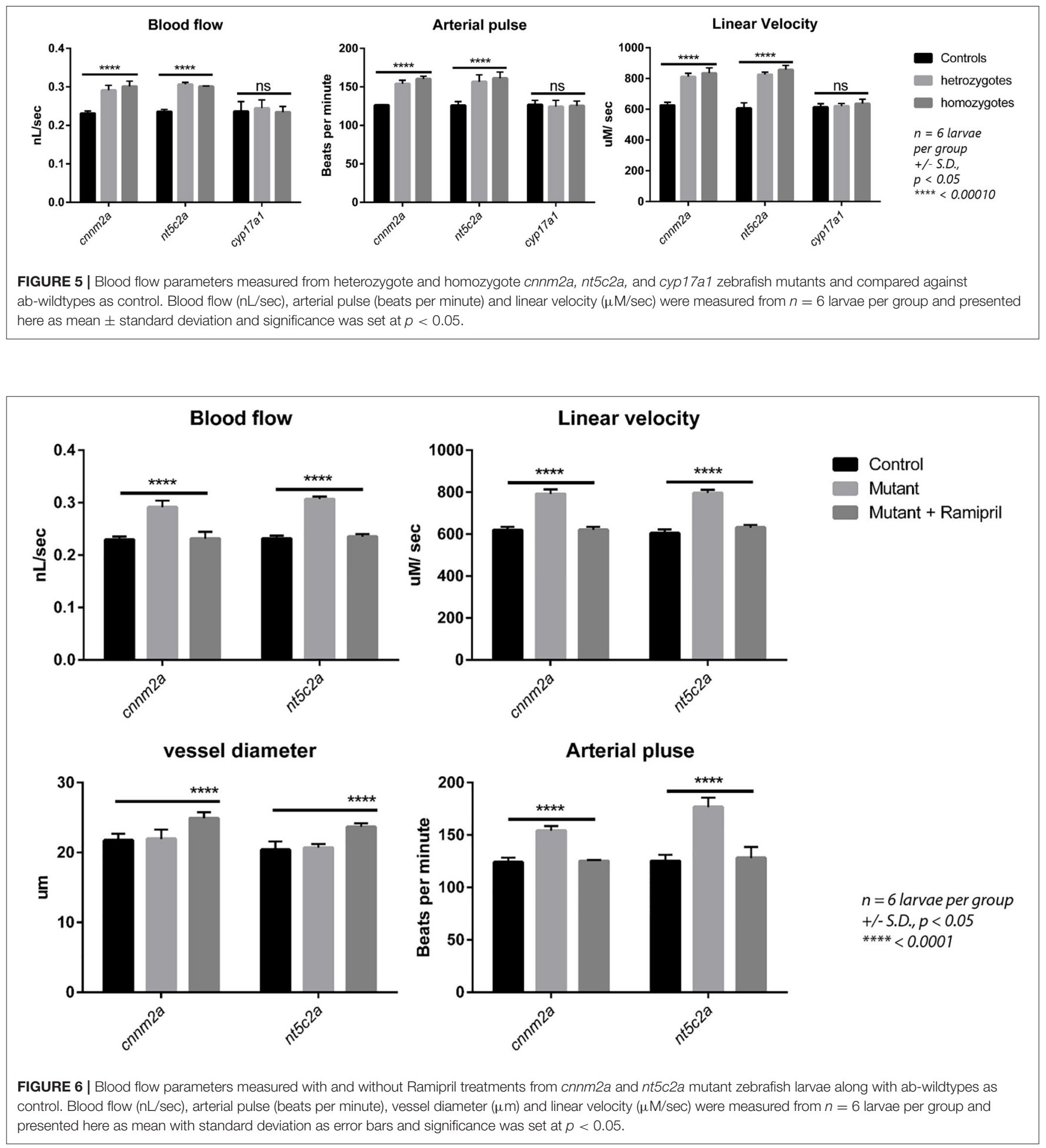

\section{DISCUSSION}

GWAS is a powerful tool for identification of novel genes and loci associated with a chosen phenotype. Evangelou et al. recently identified 535 novel loci associated with BP traits by analyzing over one million people (6). Moreover, a recent publication from our group reported 163 (and increasing) novel loci associated with CAD at a genome-wide significance level (31). A significant number of genes or loci are associated with both BP and CAD phenotypes (17). In the current study, we chose the 10q24.32 locus, which is genome-wide associated with BP and CAD. We decided to dissect the 10q24.32 locus, which encompasses 


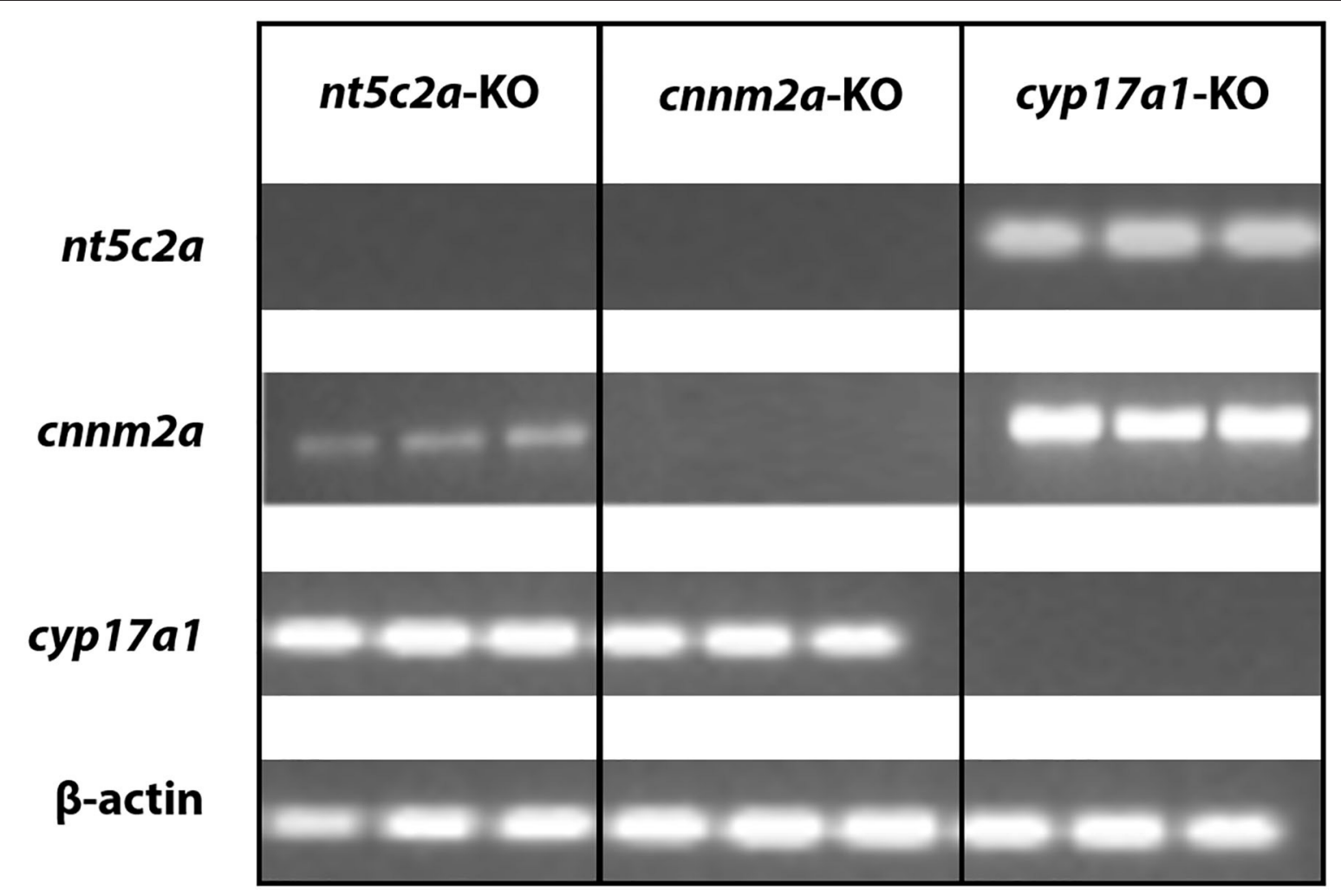

FIGURE 7 | Co-regulation of cnnm2 and nt5c2 genes. Agarose gel micrograph representing bands of DNA samples collected from cnnm2a, cyp17a1, and nt5c2a mutants. Each set of samples were investigated for expression of other genes along with house-keeping genes.
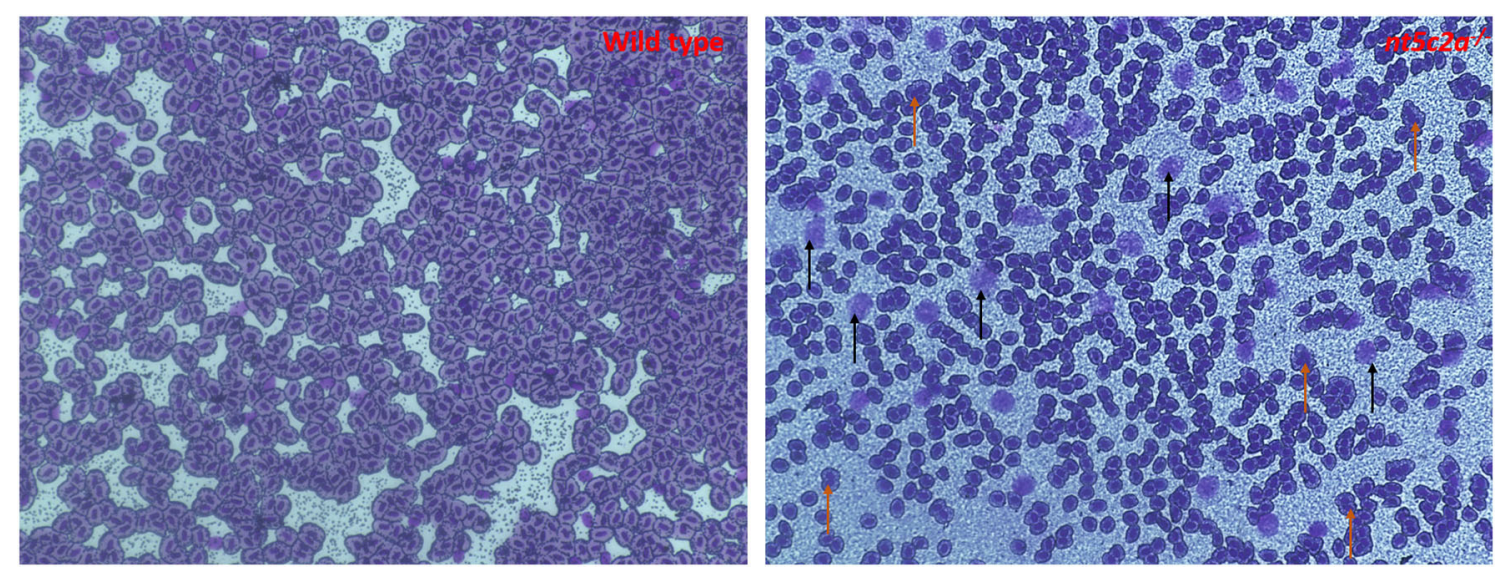

FIGURE 8 | Microscopic images of May-Grünwald-Giemsa-stained blood smear from ab-wildtype and nt5c2a mutant (heterozygote and homozygote) zebrafish larvae ( $n=6$ per group). Black arrows on the stained image from $n t 5 c 2 a$ mutant represents the groups of immature blood cells without any cytoplasmic material. Images were captured at 40X magnification. Red and black arrows on the stained image from nt5c2a mutants represents the group of multi-nucleated and immature blood cells without any cytoplasmic material respectively.

five genes CYP17A1, BORCS7, AS3MT, CNNM2, and NT5C2, focusing on the BP phenotype, with the aim of understanding the underlying pathomechanisms.

We used zebrafish as a model organism, and all five genes from the human 10q24.32 locus were found to be conserved in the zebrafish genome on chromosomes 13 and chromosome 1 as represented in Figure 1. Genome duplication in zebrafish has led to duplicate paralogs of single copy genes (10). Accordingly, the $n t 5 c 2$ and $c n n m 2$ genes have two paralogs, "a" and "b," in the zebrafish genome, mapping on completely 

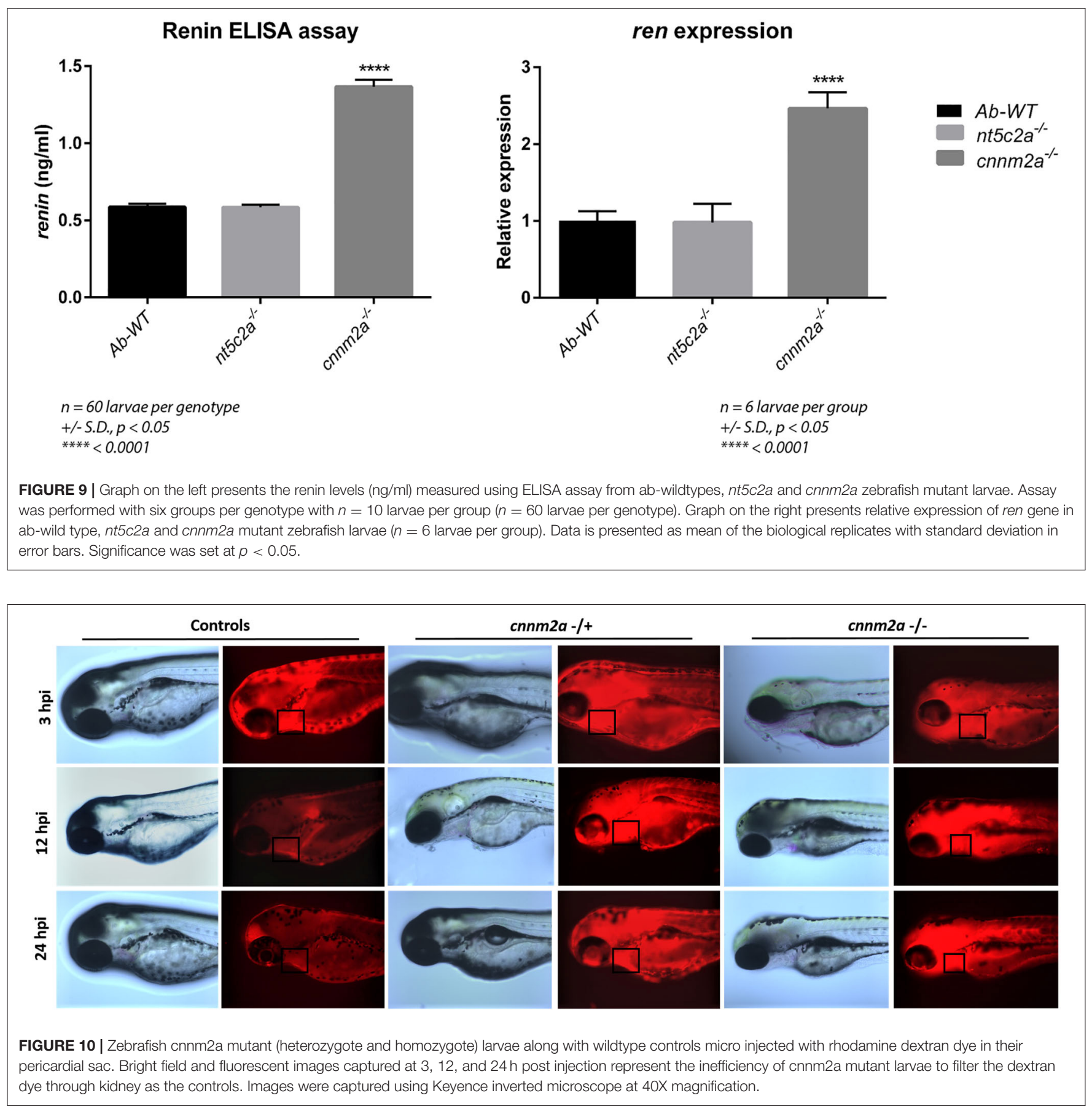

different chromosomes ("a" paralog on chromosomes 13 and "b" paralog on chromosome 1, respectively) (10). We also observed borcs 7 gene to be located in between the cyp17a1 and cnnm $2 a$ gene in chromosome 13 as highlighted in Figure 1B. Our initial experiments, using custom-designed transcription splice modification morpholinos targeting individual genes, generated interesting results, demonstrating that downregulation of $n t 5 c 2$ and $c n n m 2$ in zebrafish leads to significant alterations of blood-flow parameters; however, downregulation of the as $3 m t$, borcs 7 , and cyp17a1 genes did not result in any significant differences in those parameters. Further, no differences in vessel diameter were observed in response to downregulation of any of the five genes.

Transient downregulation using morpholinos provided useful data; however, further investigation to understand the underlying mechanism behind the observed differences in blood-flow 
parameters was warranted. Therefore, we purchased zebrafish mutant lines available from European or international zebrafish resource centers, including cnnm $2 a, c y p 17 a 1$, and $n t 5 c 2 a$ gene knockout lines. Experiments to validate the results of the morpholino assays using the zebrafish mutant lines achieved similar results. Investigations from both cnnm $2 a$ and $n t 5 c 2 a$ mutant zebrafish lead to the high blood-flow parameters; however, no difference in the vessel diameter lead us to postulate possible alterations in cardiac or renal mechanism.

We also investigated whether the high blood-flow phenotype of the zebrafish mutants could be rescued by treatment with the drug ramipril, a well-known vasodilator used as a firstline medication for humans with hypertension. Indeed, we observed dilation of blood vessels along with reversal of bloodflow parameters in the mutant larvae compared to wild types. However, it needs to be highlighted that ramipril rescues the blood-flow phenotype here via a completely different mechanism which is the direct vasodilatory effect.

Interestingly, there is a substantial literature supporting the potential of CYP17A1 as a causal gene for hypertension. Association of CYP17A1 with hypertension was first described in humans by Biglieri et al. in 1966, where they reported a gonad defect resulting in production of excess corticosterone and deoxycorticosterone and leading to hypertension (32). They also found an absence of aldosterone synthesis in subjects with normal stature and amenorrhea; however, Biglieri et al. (32), Scaroni et al. (33), and Oshiro et al. (34) also reported that only female individuals were affected and that deficiency of CYP17A1 also caused infertility. Therefore, we hypothesize that the measurement of blood flow using our system in zebrafish larvae, performed 3 days post-fertilization, may not represent the entirety of the effects of this gene, as sex determination and differentiation (which are vital to the role of cyp17a1 deficiency in human hypertension) only take place at 21-23 days post-fertilization in zebrafish (35). Nevertheless, we can report that cyp17a1-deficient zebrafish (both heterozygotes and homozygotes) were able to reproduce normally.

Both $n t 5 c 2$ gene paralogs in zebrafish are reported to have similar phenotypes in the OMIM database. Most available literature regarding the human NT5C2 gene suggests that it has a dominant role in spastic paraplegia 45 (SPG45) (36) and ALL (37). A common known phenotype associated with ALL is that it leads to the formation of immature or undeveloped blood cells (38). The blood smears staining images from $n t 5 c 2 a$ mutant zebrafish showed increased number of immature or undeveloped blood cells compare to wild types. As explained above, the platform we employed to measure bloodflow parameters computes the number and speed of blood cell movements in a defined area; therefore, the increased number of immature blood cells floating in the vasculature of $n t 5 c 2 a$ mutant zebrafish could arguably have influenced the high blood-flow parameters detected by the system. Hence, we propose that the high blood-flow parameters measured in the $n t 5 c 2 a$ mutants may not demonstrate direct causality of this gene for the phenotype, but rather may be due to the ALL kind phenotype associated with $n t 5 c 2$ gene. On the other hand, increased expression of hypertension and inflammatory markers, i.e., ace and crp in the $n t 5 c 2$ " $a$ " and " $b$ " mutants (Table 2) points toward its role in the increased blood-flow parameters. Here, we understand that the $n t 5 c 2$ gene warrants more investigations to unravel complete mechanistic pathway behind the increased blood-flow parameters in zebrafish mutants.

In the human family study, deficiency of CNNM2 has been identified in patients suffering from intellectual disability, seizures, hypomagnesemia, infertility, and altered blood pressure (39). Arjona et al. reported the role of cnnm2 gene isoforms in zebrafish using a morpholino knockdown model that caused disturbed brain development, increased embryonic spontaneous contractions, weak touch-evoked escape behavior, and reduced magnesium content, indicating an impairment of renal $\mathrm{Mg}^{2+}$ absorption (40). In another study, CNNM2 systemic heterozygotes and kidney specific homozygotes mice were reported with hypomagnesemia leading to have significantly reduced blood pressure (41). Here, we report increased blood flow, linear velocity, and arterial pulse in morpholino knockdowns of both cnnm2 isoforms in zebrafish. To further investigate the mechanism underlying the observed high bloodflow phenotype, we first validated our morpholino knockdown results in the cnnm $2 a$ zebrafish mutants. Subsequently, we detected impaired renal function in cnnm $2 a$ zebrafish mutants by renal assay. The establishment of impaired renal function in cnnm $2 a$ mutants leads to the obvious question of whether the functions of renin or aldosterone, which are the key regulators of hypertension via the RAAS pathway, are altered in this model. Since it is well-established that zebrafish do not synthesize aldosterone (42) (the main mammalian mineralocorticoid), we measured renin by ELISA assay and found that its levels were increased in lysates of $c n n m 2 a$ zebrafish mutant larvae. Expression of the ren gene (encoding renin in zebrafish), along with the inflammation and hypertension markers (ace and crp), was found significantly higher than that in $\mathrm{AB}$ wild-type controls. Overall, we conclude that $\mathrm{Mg}^{2+}$ depletion (40), increased levels of renin, and increased expression of the ren gene trigger the RAAS pathway in cnnm $2 a$ zebrafish mutants, leading to increased blood-flow parameters or hypertension.

\section{Limitations of the Study}

We understand the limitation of the current study, as well as to highlight them. (1) The 10q24.32 selected locus was identified from the GWAS in European population, therefore it might be a possibility that the mechanistic pathways suggested here may not completely be translatable to other ethnicities or ancestries. (2) cyp17a1 zebrafish mutants need to be investigated via other methods where blood flow or pressure parameters can be determined from more developed larvae (after sex maturation). (3) A zebrafish transgenic reporter line can be used for kidney $[T g(w t 1 b: E G F P)]$ and blood cells $(s d 2: T g)$ in future studies for understanding the underlying mechanisms of topics we touched briefly such as co-regulation of cnnm $2 a$ and $n t 5 c 2 a$ genes, kidney function, and its involvement in cnnm $2 a$ mutants.

In summary, we dissected the 10q24.32 locus associated with high BP in GWAS. We uncovered different potential mechanisms leading to the high blood-flow phenotype in $n t 5 c 2$ and cnnm 2 mutant zebrafish. Furthermore, this study could serve as a 
blueprint for dissection and investigation of additional loci associated with $\mathrm{BP}$, such as $13 \mathrm{q} 34,17 \mathrm{q} 11.2$, and $7 \mathrm{p} 13$, which is ongoing in our laboratory.

\section{DATA AVAILABILITY STATEMENT}

All datasets generated for this study are included in the article/Supplementary Material.

\section{ETHICS STATEMENT}

Ethical approval of the animal study was waived in accordance with the recommendations of guidelines EU Directive 2010/63/EU set by European Commission, according to this legislation Embryos and larvae up to 5 days old are excepted. The legislation criterion is: independently feeding larval forms (Directive 2010/63/EU), in other words; when the larvae are able to move through the water column independently, when their digestive tract is functional, and when they are beginning to hunt for prey which has also been simplified and published in PMID: 21726626.

\section{AUTHOR CONTRIBUTIONS}

KV conceived, designed, performed, and collected the data and wrote the manuscript. $\mathrm{CH}, \mathrm{KT}$, and JR contributed in the

\section{REFERENCES}

1. Forouzanfar MH, Liu P, Roth GA, Ng M, Biryukov S, Marczak L, et al. Global burden of hypertension and systolic blood pressure of at least 110 to $115 \mathrm{~mm}$ Hg, 1990-2015. JAMA. (2017) 317:165-82. doi: 10.1001/jama.2016.19043

2. Carey RM, Whelton PK. Prevention, detection, evaluation, and management of high blood pressure in adults: synopsis of the 2017 American college of cardiology/American heart association hypertension guideline. Ann Int Med. (2018) 168:351-8. doi: 10.7326/M17-3203

3. Muñoz M, Pong-Wong R, Canela-Xandri O, Rawlik K, Haley CS, Tenesa A. Evaluating the contribution of genetics and familial shared environment to common disease using the UK Biobank. Nat Genet. (2016) 48:9803. doi: $10.1038 / \mathrm{ng} .3618$

4. Mongeau J-G, Biron P, Sing CF. The influence of genetics and household environment upon the variability of normal blood pressure: the montreal adoption survey. Clin Exp Hypertens Part A. (1986) 8:653-60. doi: 10.3109/10641968609046581

5. Feinleib M, Garrison R, Fabsitz R, Christian J, Hrubec Z, Borhani N, et al. The NHLBI twin study of cardiovascular disease risk factors: methodology and summary of results. Am J Epidemiol. (1977) 106:28495. doi: 10.1093/oxfordjournals.aje.a112464

6. Evangelou E, Warren HR, Mosen-Ansorena D, Mifsud B, Pazoki R, Gao $\mathrm{H}$, et al. Genetic analysis of over 1 million people identifies 535 new loci associated with blood pressure traits. Nat Genet. (2018) 50:14125. doi: 10.1038/s41588-018-0205-x

7. Lieb W, Jansen H, Loley C, Pencina MJ, Nelson CP, NewtonCheh C, et al. Genetic predisposition to higher blood pressure increases coronary artery disease risk. Hypertension. (2013) 61:995-1001. doi: 10.1161/HYPERTENSIONAHA.111.00275

8. Mayer B, Lieb W, Radke PW, Götz A, Fischer M, Bässler A, et al. Association between arterial pressure and coronary artery calcification. J Hypertens. (2007) 25:1731-8. doi: 10.1097/HJH.0b013e328165cbb6 critical analysis of the data and manuscript revisions. ZA and JE supervised the project, critically analyzed the data, reviewed the manuscript, and helped in designing the initial concept of the project. All authors contributed to the article and approved the submitted version.

\section{FUNDING}

This work was supported by the DZHK (Deutsches Zentrum für Herz-Kreislauf-Forschung e.V.) and the Excellence Cluster Inflammation at Interfaces.

\section{ACKNOWLEDGMENTS}

We would like to acknowledge all the technical assistance provided by Maren Behrensen, Petra Bruse, and Sandra Wrobel. We would also like to acknowledge the support provided by our collaboration partner Fraunhofer EMB, Luebeck, for the maintenance of zebrafish lines.

\section{SUPPLEMENTARY MATERIAL}

The Supplementary Material for this article can be found online at: https://www.frontiersin.org/articles/10.3389/fcvm. 2020.00135/full\#supplementary-material

9. Fang L, Liu C, Miller YI. Zebrafish models of dyslipidemia: relevance to atherosclerosis and angiogenesis. Transl Res. (2014) 163:99-108. doi: 10.1016/j.trsl.2013.09.004

10. Howe K, Clark MD, Torroja CF, Torrance J, Berthelot C, Muffato M, et al. The zebrafish reference genome sequence and its relationship to the human genome. Nature. (2013) 496:498-503. doi: 10.1038/nature12111

11. O'Hare EA, Wang X, Montasser ME, Chang Y-PC, Mitchell BD, Zaghloul, NA. Disruption of ldlr causes increased LDL-c and vascular lipid accumulation in a zebrafish model of hypercholesterolemia. J Lipid Res. (2014) 55:224253. doi: 10.1194/jlr.M046540

12. Stoletov K, Fang L, Choi S-H, Hartvigsen K, Hansen LF, Hall C, et al. Vascular lipid accumulation, lipoprotein oxidation, and macrophage lipid uptake in hypercholesterolemic zebrafish. Circ Res. (2009) 104:95260. doi: 10.1161/CIRCRESAHA.108.189803

13. Parker T, Libourel P-A, Hetheridge MJ, Cumming RI, Sutcliffe TP, Goonesinghe AC, et al. A multi-endpoint in vivo larval zebrafish (Danio rerio) model for the assessment of integrated cardiovascular function. J Pharmacol Toxicol Methods. (2014) 69:30-8. doi: 10.1016/j.vascn.2013. 10.002

14. Staudt D, Stainier D. Uncovering the molecular and cellular mechanisms of heart development using the zebrafish. Ann Rev Genet. (2012) 46:397418. doi: 10.1146/annurev-genet-110711-155646

15. Nemtsas P, Wettwer E, Christ T, Weidinger G, Ravens U. Adult zebrafish heart as a model for human heart? An electrophysiological study. J Mol Cell Cardiol. (2010) 48:161-71. doi: 10.1016/j.yjmcc.2009.08.034

16. Margiotta-Casaluci L, Owen SF, Rand-Weaver M, Winter MJ. Testing the translational power of the zebrafish: an interspecies analysis of responses to cardiovascular drugs. Front Pharmacol. (2019) 10:893. doi: 10.3389/fphar.2019.00893

17. Newton-Cheh C, Johnson T, Gateva V, Tobin MD, Bochud M, Coin L, et al. Genome-wide association study identifies eight loci associated with blood pressure. Nat Genet. (2009) 41:666-76. doi: 10.1038/ng.361 
18. Munz M, Tönnies S, Balke, W.-T., Simon E. Multidimensional gene search with Genehopper. Nucleic Acids Res. (2015) 43:W98103. doi: 10.1093/nar/gkv511

19. Westerfield M, Doerry E, Kirkpatrick AE, Driever W, Douglas SA. An on-line database for zebrafish development and genetics research. In Seminars in Cell and Developmental Biology. Elsevier (1997). p. 47788. doi: 10.1006/scdb.1997.0173

20. Westerfield M. A Guide for the Laboratory Use of Zebrafish (Danio rerio). The zebrafish book (2000). p. 4.

21. Unger $\mathrm{T}$. The ongoing telmisartan alone and in combination with ramipril global endpoint trial program. Am J Cardiol. (2003) 91:2834. doi: 10.1016/S0002-9149(03)00230-3

22. Todd PA, Benfield P. Ramipril. Drugs. (1990) 39:11035. doi: 10.2165/00003495-199039010-00009

23. Zang L, Shimada Y, Nishimura Y, Tanaka T, Nishimura N. Repeated blood collection for blood tests in adult zebrafish. J Vis Exp. (2015) e53272. doi: 10.3791/53272

24. Christou-Savina S, Beales PL, Osborn DP. Evaluation of zebrafish kidney function using a fluorescent clearance assay. J Vis Exp. (2015) e52540. doi: 10.3791/52540

25. Mirsaeidi M, Omar HR, Ebrahimi G, Campos M. The association between ESR and CRP and systemic hypertension in sarcoidosis. Int J Hypertens. (2016) 2016:2402515. doi: 10.1155/2016/2402515

26. Penn state YL. 4C Browser. (2018). Available online at: http://promoter.bx.psu. edu/hi-c/virtual4c.php (accessed September, 2018).

27. Dieck C. Mechanisms and Therapeutic Targeting of NT5C2 Mutations in Relapsed Acute Lymphoblastic Leukemia. Doctoral thesis. Columbia University, Columbia. (2018).

28. Meyer JA, Wang J, Hogan LE, Yang JJ, Dandekar S, Patel JP, et al. Relapsespecific mutations in NT5C2 in childhood acute lymphoblastic leukemia. Nat Genet. (2013) 45:290-4. doi: 10.1038/ng.2558

29. de Man FS, Tu L, Handoko ML, Rain S, Ruiter G, François C, et al. Dysregulated renin-angiotensin-aldosterone system contributes to pulmonary arterial hypertension. Am J Respir Crit Care Med. (2012) 186:7809. doi: 10.1164/rccm.201203-0411OC

30. Drayer JI, Weber MA, Sealey JE, Laragh JH. Low and high renin essential hypertension: a comparison of clinical and biochemical characteristics. Am J Med Sci. (1981) 281:135-42. doi: 10.1097/00000441-198105000-00003

31. Erdmann J, Kessler T, Munoz Venegas L, Schunkert H. A decade of genomewide association studies for coronary artery disease: the challenges ahead. Cardiovasc Res. (2018) 114:1241-57. doi: 10.1093/cvr/cvy084

32. Biglieri EG, Herron MA, Brust N. 17-hydroxylation deficiency in man. J Clin Invest. (1966) 45:1946-54. doi: 10.1172/JCI105499

33. Scaroni C, Biason A, Carpené G, Opocher G, Mantero F. 17-alphahydroxylase deficiency in three siblings: short- and long-term studies. $J$ Endocrinol Invest. (1991) 14:99-108. doi: 10.1007/BF03350278
34. Oshiro C, Takasu N, Wakugami T, Komiya I, Yamada T, Eguchi Y, et al. Seventeen alpha-hydroxylase deficiency with one base pair deletion of the cytochrome P450c17 (CYP17) gene. J Clin Endocrinol Metab. (1995) 80:25269. doi: 10.1210/jcem.80.8.7629254

35. von Hofsten J, Olsson P-E. Zebrafish sex determination and differentiation: involvement of FTZ-F1 genes. Reprod Biol Endocrinolo. (2005) 3:63. doi: 10.1186/1477-7827-3-63

36. Straussberg R, Onoufriadis A, Konen O, Zouabi Y, Cohen L, Lee JY, et al. Novel homozygous missense mutation in NT5C2 underlying hereditary spastic paraplegia SPG45. Am J Med Genet Part A. (2017) 173:310913. doi: 10.1002/ajmg.a.38414

37. Tzoneva G, Perez-Garcia A, Carpenter Z, Khiabanian H, Tosello V, Allegretta M, et al. Activating mutations in the NT5C2 nucleotidase gene drive chemotherapy resistance in relapsed ALL. Nat Med. (2013) 19:36817. doi: $10.1038 / \mathrm{nm} .3078$

38. Scotti F. Automatic morphological analysis for acute leukemia identification in peripheral blood microscope images. In CIMSA 2005 IEEE International Conference on Computational Intelligence for Measurement Systems and Applications 2005 (Giardini Naxos: IEEE) (2005). p. 96-101.

39. Giménez-Mascarell P, González-Recio I, Fernández-Rodríguez C, Oyenarte I, Müller D, Martínez-Chantar ML, et al. Current structural knowledge on the CNNM family of magnesium transport mediators. Int J Mol Sci. (2019) 20:1135. doi: 10.3390/ijms20051135

40. Arjona FJ, de Baaij JH, Schlingmann KP, Lameris AL, van Wijk E, Flik G, et al. CNNM2 mutations cause impaired brain development and seizures in patients with hypomagnesemia. PLoS Genet. (2014) 10:e1004267. doi: 10.1371/journal.pgen.1004267

41. Funato Y, Yamazaki D, Miki H. Renal function of cyclin M2 $\mathrm{Mg} 2+$ transporter maintains blood pressure. J Hypertens. (2017) 35:585-92. doi: 10.1097/HJH.0000000000001211

42. Wilson K, Tucker C, Al-Dujaili E, Holmes M, Hadoke P, Kenyon $\mathrm{C}$, et al. Early-life glucocorticoids programme behaviour and metabolism in adulthood in zebrafish. J Endocrinol. (2016) 230:125-42. doi: 10.1530/JOE-15-0376

Conflict of Interest: The authors declare that the research was conducted in the absence of any commercial or financial relationships that could be construed as a potential conflict of interest.

Copyright (C) 2020 Vishnolia, Hoene, Tarhbalouti, Revenstorff, Aherrahrou and Erdmann. This is an open-access article distributed under the terms of the Creative Commons Attribution License (CC BY). The use, distribution or reproduction in other forums is permitted, provided the original author(s) and the copyright owner(s) are credited and that the original publication in this journal is cited, in accordance with accepted academic practice. No use, distribution or reproduction is permitted which does not comply with these terms. 